\title{
Boreal Conference 2006 \\ Synopsis of presentations and plenary discussion periods October 2-3, 2006
}

\author{
by Guy K.M. Smith 1,2
}

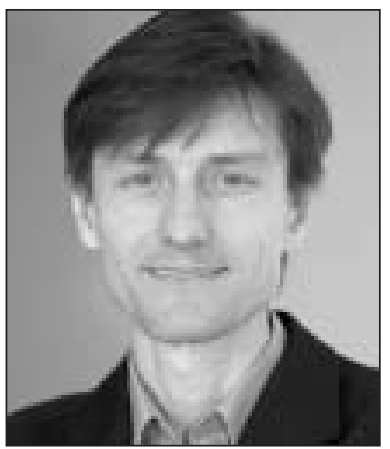

Guy K.M. Smith

\begin{abstract}
Introduction
From its opening pages of three years ago, Boreal Conference 2006 had a story to tell. It followed an outline put together by conference organizers with four main chapters: Climate Change as a Driver of Change; Globalization and Community Sustainability; Natural-Disturbance-Based Management; and Balancing Protection and Use. The theme running through the story was one of
\end{abstract} change; social, economic and environmental. What happened between the opening and closing words was a product of informed presenters and thoughtful questioners, and time in the program to allow them to exchange knowledge and ideas. It is hoped that the following digest will provide enjoyable reading; a chance to revisit the event for those who were there, and chance for others to read the story.

\section{Session I. Climate Change as a Driver of Change}

Over the two-week period leading up to the Conference Moderator Suzanne Parton, CS Enterprises/Moose Cree First Nation, collected a number of news clippings about climate change from a wide range of media. She read excerpts to illustrate the public interest in the issue during her opening remarks. She also related the impacts of climate change felt by communities, such as the lack of winter road access to remote Aboriginal communities.

With reference to current climate models, Keynote Speaker David Pearson, Laurentian University, presented an overview of the science of global change and the likely climate future for the planet. His overall message was that, if data and interpretations prove correct, the Earth will become a distinctly different place over the next 50 years. Change has been particularly rapid over the past 30 years and is without precedent in the past 1000 years and quite likely the past 60000 years. Such change will involve extinctions of species and ecosystems, with the Boreal region being particularly affected. While much attention has been given to understanding the physics of climate and the modeling of general climate change, there is a need for reliable regional models. Science is capable of delivering such models, which would be put to good use by natural resources managers. Pearson emphasized the profound effects of increased evaporation rates, which are evident in reduced water levels and drought conditions over large areas. Precipitation, he said, is more variable, localized and difficult to model. In the final analysis, a sustained increased rate of evaporation has a much greater impact than fluctuations in precipitation levels.

It was pointed out during the questions and discussion following the Keynote Presentation that Hudson Bay presents uncertainty in climate models known as the "Hudson Bay effect." This large body of relatively shallow water is an island of high temperature, and a lack of winter ice over the bay reduces albedo. There was further discussion of an area over Alberta, which appears to be very warm on a map of North American thermoclines. This phenomenon is attributed to the winter of 2005, which had temperatures well above average and should not necessarily be taken as indicative of future temperatures.

Discussion turned to how the boreal forest should be managed, given what is known and predicted about climate change. Pearson emphasized that the boreal region is not just a forest; it is a major carbon store for the planet. A questioner noted that temperature extremes have greater effects on animals than temperature averages, and asked if we should not be more concerned with the extremes. The response was that means tend to disguise the extremes, and it is important in the study of impacts to look at seasonal changes and the frequency of extreme conditions.

When asked how great an effect wood burning for home heating has on the carbon balance, Pearson said it is a question of scale and a question of tradeoffs. Wood burning for heat is not a significant contributor to atmospheric carbon, and wood is a renewable source of heating fuel. As a source, it is part of the present day rather than fossil section of the carbon cycle so it has less of an impact than coal-fired generation, although there are other factors to consider, such as the effects of smoke on human health.

Discussion turned to the differing albedo of coniferous and deciduous tree cover. If conifers are cleared from the land there is a cooling effect, because conifers tend to absorb and hold more heat than deciduous trees.

Methane has a profound effect on increasing the greenhouse effect. Methane is being released via permafrost melting and more open exposure of beaver dams. The wildcard is whether the methane stored in sediment on the ocean floor will be released by warming ocean water. If changes occur in ocean temperatures at lower levels, there could be a substantial release of methane, which would intensify global warming.

We are past the point of debating whether humans are contributing to climate change. Now is the time to assess vulnerabilities and exposure to climate change and develop

\footnotetext{
${ }^{1}$ Guy Smith was Co-Chair of Boreal Conference 2006. He acknowledges the contributions of presenters and moderators whose presentations and discussion points are summarized herein, and who reviewed this paper.

${ }^{2}$ Natural Resources Canada, Canadian Forest Service, 1219 Queen St. E., Sault Ste. Marie, Ontario. Email: gusmith@nrcan.gc.ca
} 
adaptation strategies, according to Panel Speaker Mark Johnston, Saskatchewan Research Council. His presentation emphasized the need to develop some forward-looking scenarios of the effects of changing climate, with socio-economic factors given as much attention as biophysical considerations. It is likely that policy changes will become necessary. For instance, there may be cause to re-examine rotation ages or re-evaluate the use of exotic species in regeneration. Increased fire activity will have implications for budgets and resources; to continue what we are doing now will not be an option. Socio-economic assessments will be important in helping to meet changing societal needs as forest conditions change and demand increases for non-timber forest products and bio-energy production. The loss of forest monitoring programs has caused a dire situation in Canada, contended Johnston, who advocated for a robust, standardized national monitoring system to indicate where and how the forest is changing. As did the keynote speaker, Johnston pointed to the need for good regional models with the necessary resolution for resource management decision-making.

Based on studies of Canada's National Parks System, Panel Speaker Daniel Scott, University of Waterloo, made a case for climate change adaptation strategies for protected areas. It is estimated that 50 percent of the system will experience some degree of biome change in the future with associated shifts in ecotones and species composition.

Critical questions for protected area managers are: how much should be invested in maintaining habitat for species that may be disappearing (e.g." "keystone" species such as the polar bear); how to manage for the invasion of species formerly not within an ecotone; how to manage visitor expectations (e.g., accepting the disappearance of glaciers or loss of waterfront); and what stresses may be introduced by a forecasted increase in park visitation. Policy issues include the need to re-examine definitions in the Species at Risk Act as species move beyond historic ranges. Scott further suggested that climate change be considered in park system planning, park establishment, and fire management policy. He concluded with the point that a climate change adaptation policy is needed for both National and Provincial Park Systems across the Boreal Zone.

The Panel Session discussion period considered the tradeoff between short and long rotations in terms of impacts on carbon balance. Johnston said that it is a question of timing: when do you want the benefit? Lengthen rotation age and increase the proportion of old growth, and you'll have increased carbon storage. But this carries the risk of fire, which causes a massive release of carbon. Shorten rotation age and you'll have more frequent renewal and more young growing trees to capture carbon. Harvested wood stores carbon in forest products. He offered the personal opinion that we will never see the day when forests are managed just for carbon because of their many other values. The key questions are how to maximize carbon management while recognizing other non-carbon values, and how to optimize multiple benefits.

An opinion offered by a member of the audience was that forest management can do little to influence the huge storage and release of carbon by forests. The impact of management in the boreal forest is insignificant compared with the impact of fire, which can cause emissions to double in a bad season, and humans can do little to mitigate this impact. This is not to mention the vast forests of Russia, which are not managed to Canadian standards. Another participant stated that afforestation has many benefits besides carbon budget value, and that it is important to look at other economic benefits. A closing point on this line of discussion was that fossil fuel consumption is the part of the equation that humans definitely can influence.

A questioner asked what kinds of surveys are needed to develop federal and provincial policy, and specifically, what "real-world" strategies can be employed "on-the-ground" to identify priority conservation areas. In response, it was offered that surveys will help to identify how to do business in different ways to account for climate change, and that surveys also help to raise awareness of issues, perhaps their main function at this time. Canadians need to have a dialogue on what is expected for protected areas such as National Parks. In response to the question of whether there are protocols for what we should monitor, a panellist said that Parks Canada is asking this question and is looking for key indicators that will vary by region and jurisdiction. There is a need to have broader discussions about monitoring in Canada.

Picking up on the need for reliable regional models, a participant asked whether pollen analysis and soil science have been employed to help understand regional changes now compared with changes that occurred 4000 to 6000 years ago. The response included the point that in the past, newly glaciated landscapes provided starting points for ecological succession, whereas today, competition barriers to plant succession are in place. Consequently, soil and pollen analyses alone do not provide enough information for making predictions. Another respondent added that the rate of change today is more rapid than at any time in the recent glacial past, so adaptation mechanisms will have difficulty handling the rapid rate of change. This could mean that ecological associations will change rapidly, making our field guides less relevant and less accurate.

Another participant asked how community capacity can be enhanced, considering demographic forecasts, and whether communities are ready to make land-use decisions. In Saskatchewan the issue of community capacity is very important. However, communities are grappling with many pressing issues aside from climate change adaptation. The new Forest Communities program will entertain proposals regarding community participation. Other questions were posed, but not answered. (Will provincial governments see value in transferring land management to communities? Will this even be a desirable option for communities? With the forest industry in decline, will there be a new model for Crown land management?)

\section{Session II. Globalization and Community Sustainability} In her opening remarks, Moderator Peggy Smith, Lakehead University, spoke of the changing world order and its affect on war, oil and gas prices, and trade. These trends are having an impact on people in the workplace and in their personal lives.

Use of terms "globalization" and "Aboriginal communities" in the same sentence is not intuitive, according to Keynote Speaker, Garry Merkel, Consultant with Ktunaxa Nation, who noted that Aboriginal communities tend to be remote, land-based and less prepared for change coming from places far away. Aboriginal peoples notice that the land is changing. They see changing migration patterns of caribou, 
permafrost melting, expansive Mountain pine beetle infestations, disappearance of some medicinal plants, and the loss of travel corridors. For the first time in living memory, there was no wild rice season in northern Saskatchewan in 2006 because water levels were too high. "The land is changing literally under your feet, and this is very scary for people who live on the land," said Merkel.

Social changes are also sweeping through native culture, having a stressing effect on communities. Aboriginal communities are moving at an unprecedented pace of change as they build capacity to administer education, health, and social services and establish systems for public accountability, in manners different from traditional governance. However, the increased international scrutiny (as required under Forest Stewardship Council Principle 3) is increasing the ability of Aboriginal people to protect traditional interests in land. Merkel listed a number of Aboriginal interests in land management, chiefly protecting valued areas (cultural and ecological), fulfilling stewardship responsibilities, increasing local involvement and employment, and reducing impacts on the land. The forest sector needs to change the way it works with Aboriginal community, and Forest Stewardship Council (FSC) principles provide a good framework. "People who have lived on the land for thousands of years should know something about it," concluded Merkel.

During the questions and discussion following the Keynote Presentation, the point was made that when Chiefs participate in land-use plan consultations, the whole community participates. Relationship building means spending time doing things together that are useful, and that little things make a difference. A questioner commented that self-government is costly and asked where the financial assistance will come from. Merkel responded that many communities are not governing themselves effectively because they lack capacity. He said that self-governance happens in the mind long before it becomes reality. People have to believe before they can make it happen. Self-government takes time, builds gradually, and requires sustained belief and commitment. When asked about the distinction between history and heritage, Merkel responded that effective working relationships are about bringing experience to the table, and the key is to recognize the experience and listen to it.

Merkel was asked how challenging it would be for Aboriginal communities to apply results-based performance indicators to projects under government programs, such as the new Forest Communities Program. He answered that such indicators can be developed for Aboriginal communities, and mentioned the Clayoquot Agreement as a good example. The development of indicators can be challenging for any remote community, not just Aboriginal, he said.

When asked how well the Great Bear Rainforest Agreement is working, Merkel said that under the Constitution Act, the Parliament of Canada has Section 91 powers and the Provincial legislatures Section 92 powers. First Nations cannot have "flat-out" authority for land management, but should build solid working relationships with the bureaucracy. "The bureaucracy is very powerful, and it can make or it can kill a political leader," said Merkel.

Panel Speaker Larry Innes, Canadian Boreal Initiative, spoke of the global opportunity in Canada's boreal forest, given the sheer expanse of the biome combined with the Canadian traditions of pluralism and the rule of law.
Ecosystem services provided by the boreal forest in Canadasuch as water filtration, natural control of pests, and carbon storage-are estimated at $\$ 93$ billion per year. Canada remains one of the world's last frontiers of intact forest, and the Canadian Boreal Initiative (CBI) is working to conserve the landscape, with recognition of the long-standing use of the land by indigenous peoples. The new conservation paradigm accepts the presence of people on the landscape and accommodates native use. Innes cited several international agreements that reinforce this principle, including the Rio Declaration on Environment and Development and the Canadian Biodiversity Strategy. CBI is promoting adoption of the Boreal Conservation Framework, which has been endorsed by a number of private and not-for-profit organizations, as a means to ensure conservation of boreal ecosystems. He emphasized the value of maintaining relationships with those responsible for land management decisions over large areas, providing examples of cases where CBI works with First Nations at the invitation of First Nation leadership. CBI is also working with forest companies, who in Canada often have management responsibilities through tenure arrangements over large areas. Companies are increasingly recognizing the value of Forest Stewardship Council certification, which provides a business case for their participation in the Framework.

The needs of small resource-dependent communities are not part of the analysis as large corporations restructure to meet demands of globalization. However, communities can respond to global trends with strong leadership, development of human capital, and promotion of local entrepreneurship, according to Panel Speaker Luc Bouthillier, Laval University. $\mathrm{He}$ cited the example of Sweden, a nation that is focusing on efficient supply chain management and higher product value. Labour productivity is supported by public policy that involves investments in infrastructure, computer literacy, and training. In Canada by contrast, Bouthillier has observed what he terms an "addiction" to forest industry that has tended to decrease educational attainment, reduce entrepreneurship, lower female participation in the economy, and weaken the growth of the service sector. He sees the condition changing as communities redefine relationships and institutions so that economic viability is maintained. Community resiliency is expressed in a long-term vision of land occupancy, understanding of the attachment to place, and diversification of local economies based on an understanding of global trends. A good example is the move in Quebec to decentralize and regionalize forest policy and encourage social capital development at the local level.

The Lac La Ronge Woodland Cree First Nation is a boreal community taking the initiative to meet the challenge of a global economy. It is the largest First Nation in Saskatchewan and one of the 10 largest in Canada. Chief Tammy CookSearson, Panel Speaker, is helping to make the Band's strategic plan a living reality through educational, economic and social development for the 8600 Band members living in six reserve communities. She acknowledges that today's progress is built on years of strong First Nation leadership and the contributions of elders who provide knowledge of the Woodland Cree culture, language, and traditions that will sustain the communities into the future. Unfortunately, demands of strategic economic development kept the Chief in Lac La Ronge at the time of Boreal Conference 2006. Deborah 
Weedon, Saskatchewan Environment, who is working closely with the Band on an integrated forest land use plan, was able to step into the role of panel speaker at short notice. She articulated the Band's goal of securing a forest management agreement and managing the landbase according to its belief that "traditional lands and the resources they contain are a heritage from our ancestors and must be maintained as a legacy for our children." Economic diversification is being attained through the business arm of Lac La Ronge First Nation, called Kitsaki Management Limited Partnership. The English meaning of the name is, "take your coat off and get down to work," and fittingly Kitsaki's vision is to build a diverse network of businesses to improve the economic future for Band members, other Aboriginal people, and all other stakeholders. Business interests include a sawmill partnership, catering, resort operations, wild rice production, trucking, and insurance services.

In the Panel Session discussion period a question was posed about the role for ecological economics. A response was that green accounting is very important, and we need to try to put prices to values such as water and air. In our current system, for example, the cost of water used to produce oil is externalized. On the matter of putting a price on living in a forestdependent community, Bouthillier offered the view that what really matters is people knowing why they enjoy living in the community. In response to the question, "how can people form relationships with the land when the economy demands they move around to hold jobs?" his response was that globalization should not be allowed to "become your master." Face it and acknowledge it, and find a way to develop jobs in rural communities, he said. It was noted that research has shown that it is easier for people to have a sense of control over their lives in rural versus urban communities. A participant questioned why there are no territorial or provincial partners in the Canadian Boreal Initiative. The answer was that there are agreements in place on specific initiatives with Newfoundland, Alberta, and Northwest Territories and other agreements are in the works on particular issues. Initially, provinces and territories were not involved because CBI aimed to get out in front of issues ahead of government policy.

\section{Session III. Natural-Disturbance-Based Management - where are we and where are we going?}

Moderator Barry Waito, Louisiana Pacific Corp., opened the session by stating that making changes to policy is challenging, especially when the change affects a large landbase that spans jurisdictions. Waito, who attended the National Forestry Congress in Ottawa the week before Boreal Conference 2006, said that the congress identified needs for policy change, particularly in connection with cumulative impacts of resource use across Canada's boreal landbase.

Keynote speaker Yves Bergeron, Université du Québec en Abitibi-Témiscamingue, presented a rationale for using the natural disturbance model and forest dynamics as templates for silviculture. Under a natural disturbance paradigm, forests would be managed within the range of natural variability along the key disturbance axes of frequency, size, and severity. In portions of the boreal forest with relatively long fire cycles, such as in northeastern Ontario and northwestern Quebec (the Claybelt), there is a high probability of having old forest stands. In such forests the multi-cohort model of stand development is a useful template for planning silviculture over large areas. Management approaches to maintaining third cohort characteristics include protected areas, increased rotation lengths, and adapted silviculture to replicate older forest stand structure. A natural disturbance approach would emulate a range of sizes of disturbance patches surrounded by a mosaic of uncut forest, with size and dispersion pattern influenced by the historic fire cycle.

Emulating fire severity is also important, as fire does not kill all trees, and trees still standing following a fire may continue to produce seed for some time. Bergeron discussed the role of duff layer disturbance in prompting plant community succession. Low-severity fires tend to favour the accumulation of organic matter whereas high-severity fires tend to promote decomposition and increased site productivity. He closed his presentation with the comment that the implementation of natural disturbance-based management has been very slow, and that government-industry partnerships are necessary to share the risk and the costs of implementation.

During the questions and discussion following the Keynote Presentation, it was stated that policy change in Quebec is creating a more supportive environment for companies to undertake natural disturbance-based management. A challenge is that a fully allocated timber supply does not leave much buffer for trials. A question about soil drainage led to a discussion of paludification, which is inherent on lowland Claybelt sites. Another comment from the audience was that other factors besides time since fire determine stand structure. There is complexity in the first cohort following disturbance, and secondary disturbances such as insects, wind, and ice, contribute to gap replacement dynamics. A questioner argued that we should not be constrained to manage within the range of natural variability and that we have the intelligence and know-how to redesign landscapes to suit our objectives. The response to this point was that natural disturbance-based management serves as a good benchmark and it is better to follow processes and patterns that are in place. We can aim neither to mimic nor recreate nature. We ought to work within extremes. The question of the carbon budget was raised, and it was pointed out that older black spruce systems permit little carbon sequestration. A component of aspen on the landscape permits greater $\mathrm{CO}_{2}$ capture and tends to reduce the accumulation of mosses and the associated paludification.

Panel Speaker Craig DeLong, British Columbia Ministry of Forests and Range, spoke about a new landscape-level planning approach for northeastern $\mathrm{BC}$ that replaces the biodiversity guidebook, including the refinement to natural disturbance units. The new approach is being implemented in the former Prince George Forest Region, which is now part of the Northern Interior Forest Region. The new approach supports management decisions concerning old growth, patch size distribution, and emulating disturbance dynamics. The natural range of variability (NRV) for amount of old forest was estimated for large geographic areas (i.e., > 100000 ha) that have similar climate and topography and the impacts of meeting various targets based on NRV tested. Legislation now requires a target based on a minimum NRV. Attempting to move towards a natural patch size distribution is proving to be more complicated but a greater range of patch sizes is being achieved. A strategy for affording more intact old forest areas is to intensify management on a smaller number of sites to achieve increased volumes from reduced area. 
A review of independent audits of forest management in Ontario caused Panel Speaker Trevor Hesselink, Wildlands League, to critically question how effectively management emulates natural disturbance on Ontario's Crown forests. $\mathrm{He}$ observed that efforts to determine pre-industrial forest condition are often weak, and the highly variable quality of inventory data and monitoring makes it difficult to determine current forest condition. Hence, it is difficult to assess how well we are emulating natural disturbance. He suggested that the spirit of emulation seems to be missing in Ontario's approach, and that we seem stuck on selective "mimicry" instead. In examining Ontario's Crown Forest Sustainability Act, he also found layers of meaning in the terms "sustainability" and "forest health." The caveats "within the limits of silvicultural requirements," and "while providing for the needs of people" seem to suggest imposed value judgments in favour of economic drivers, he argued, adding that economic cycles differ greatly from ecological cycles. In his closing comments he asked whether we would truly be using resources in the same manner if sustainability of communities was our main objective, highlighting divergence from an even more traditional sustainable development test.

Panel Speaker Margaret Donnelly, Louisiana Pacific Ltd., presented a natural disturbance-based forest management planning approach for an area in the Duck Mountains of Manitoba that is subject to long fire cycles. The preferred management scenario, modeled with Patchworks wood supply model, maintains an age class distribution across the landscape that reflects the relationship between fire frequency and forest structure. The plan maintains 20000 ha to 30000 ha of older forest throughout the unit, though these areas change over time. Donnelly stressed that it is impossible to manage for all species at all times in all places. Desirable habitat is forecast to remain static in many areas (e.g., protected areas, inoperable areas) while additional older forest habitat will be found in different areas of the landbase over the long-term planning horizon. A variety of silviculture treatments will be employed to meet management objectives including leave for natural, understory protection, plant and tend, and variable retention. Effects monitoring and ongoing research will form part of the adaptive management cycle inherent in the plan.

The Panel session discussion period opened with the question of whether we should emulate past or potential future natural disturbance under a changed climate. The response was that some things do not change. For instance, natural disturbances will never make square disturbance patterns with even dispersion. We can apply certain rules no matter how the climate changes. Zones can shift, depending on changing climate, and we can adapt the classification system accordingly. Another question addressed social concerns about large cutover patch size and asked how policy makers reconcile the tension between natural disturbance science and social concerns. The response was that it is important to separate temporal from spatial changes, and that the rate of logging is more important than the size of openings. A question was asked about how big an area is needed to emulate natural disturbance within natural variation. The response was that bigger is better, but the size should be subject to societal concerns. Very large disturbance patches are likely to occur anyway because of wildfire. What counts is keeping ecological processes functioning for the long term. It is perhaps more important to emphasize process over pattern.
In a discussion of public acceptability, fixed reserves as strict no-cut areas were considered to be more acceptable than rotating reserves where stand replacement is a bigger factor. Also, the public tends to be more accepting of irregularly shaped cutovers.

In response to the question of uncertainties and whether in the end we are not just "rolling the dice," it was said that decisions will be made with or without good information and models. Our aim should be to reduce uncertainty as best we can. We are striving to build ecosystem resilience to help systems better handle a variety stresses over time.

There was a question of whether we should be conserving the duff layer for carbon storage as opposed to disturbing the duff layer to stimulate nutrient cycling. The response was that our forest management methods have tended to favour the accumulation of forest floor more than occurs under the natural regime, so it makes sense that we should be able to disturb the duff layer some, though it depends on stated objectives. Ideally we want to optimize both productivity and the carbon budget. Both considerations need to be brought to the table when objectives are developed. It was noted that the Manitoba Model Forest is implementing natural disturbance trials to apply science knowledge, with information available at www.manitobamodelforest.net.

\section{Session IV. Balancing Protection and Use}

In his opening remarks Moderator Al Willcocks, Saskatchewan Forest Service, spoke of the importance of allowing people who live and work in the forest to make decisions about land management. He commented that balancing depends upon who has their hands on the balance, and that the wishes of local people can be overpowered by agendas from places far removed from forest communities.

Keynote speaker Mike Martel, Tembec Inc, began with a sober look at the massive change in Canada's forest industry and moved to a discussion of innovation, which has always been critical to competitiveness. He pointed to increased demand for Canadian pulp owing to its superior quality, the Canadian invention of oriented strand board and our leadership in that market, and Canadian softwood lumber mills as among the most efficient in the world. Consolidation of the industry will increase demand for wood fibre. Tembec aims to increase forest productivity through the application of research in areas such as improved growth and yield prediction, tree improvement, spatial modeling, commercial thinning, and enhanced forest inventory. The company is an industry leader in forest research and an active player in several research partnerships. He emphasized the importance of collaboration between government and industry in the planning and implementation of enhanced forest productivity.

Questions and discussion following the Keynote Presentation covered security of tenure, consolidation of forest innovation capacity in Canada, and silvicultural investments by industry. Tenure is a big issue for industry in Canada and Mr. Martel stated that he thought the issue could be worked out in Ontario. He applauded the move to amalgamate national research institutes in Canada and the formation of the Fibre Centre within the Canadian Forest Service. He referred to a "disconnect" between markets and the supply chain, and stated that Tembec wants to see substantive gains in growing forest fibre, just as the industry has seen gains in product innovations over the years. As an example he 
mentioned tree breeding for improved form and fibre characteristics.

One question in particular generated considerable interest and a series of comments from the floor. It was posed by a forestry student, who asked why the J.D. Irving company in New Brunswick makes substantial investments in tree improvement and silviculture, but the same level of spending does not appear to be happening in Ontario. Mr. Martel's response referred to the poorly defined business case for silviculture, a need for better industry-government partnerships, and an excess of time spent meeting process demands. He said that business requires secure fibre supply for the short and long terms and that an examination of inputs and outputs is part of the long-term business case. A comment from the floor referred to visionary people of the past-people in industry and government—who had drive and commitment to make things happen. Other comments addressed the demands of consensus-building and stakeholder input, which have added process and complexity in order to address the loss of trust in forestry.

Panelist John McNicol, Forestry/Wildlife habitat consultant, provided an historical perspective on the question of "balancing protection and use-whose finger is on the scale?" He traced the evolution of forestry in Ontario beginning with the 1960s, an early industrial period with few restrictions on logging and very little road access. The 1970s and early 1980s were generally a very good time for the industry with strong political support and minimal challenges by the environmental movement or First Nations. Challenges to forest management and the need for wider-ranging habitat guides surfaced in the 1980s with the Class Environmental Assessment for Timber Management on Crown Lands in Ontario. A result of the Class EA was increased public participation and information-sharing, leading to the 1990s, a period McNicol titled "The Peoples' Forest." Currently, forest management is giving much attention to natural disturbance pattern emulation and managing forests as ecosystems. He concluded that in the $21^{\text {st }}$ Century the finger of Mother Nature is on the scale.

Canada's boreal forest contains approximately $35 \%$ of the world's wetlands. The Hudson Bay Lowlands represent the world's largest wetland complex. Up to $50 \%$ of the continental waterfowl population resides in the boreal region for some part of the year. These were among the facts related by Panellist Chris Smith, Ducks Unlimited Canada, who further pointed out the valuable ecosystem services provided by the boreal forest, including water filtration, flood control, carbon storage, and wildlife habitat. This natural capital is potentially threatened by an increased rate of industrial development.
Furthermore, the influence of these activities on boreal wetlands is poorly understood, partly because of the lack of inventory. Ducks Unlimited Canada advocates a balanced approach to boreal conservation with lands managed in a sustainable fashion and integrated with a network of protected areas. These land-use decisions need to be supported by public and corporate policies that promote and support the principles of conservation. We need to understand boreal wetland ecology and hydrology to develop an understanding of the risk of development, including roads, on watersheds (e.g., water yield and water quality). Smith called for a collaborative approach and a sharing of responsibilities to learn, and develop conservation solutions that make sense. An example of collaborative watershed-based forest planning projects being undertaken in the western boreal forest was presented.

The need for data-sharing was emphasized by Panelist John Riley, Nature Conservancy of Canada. He pointed out that currently data are divided among various federal and provincial agencies. There has to be improved data-sharing and analysis to enable characterization of the landscape at the appropriate scales, he said.

The Panel Session discussion period began with the question of what portion of the forest landbase should be allocated to management for enhanced forest productivity. Provincial policy is needed before the question can be answered. Other comments from the floor were that the balance between protection and use depends upon how closely one looks at the balance (a question of scale), and that the balance depends upon who is sitting at the table to make the decisions. Riley shared his concern that society lacks information at the appropriate scale to support decisions.

\section{Conclusion}

One of the last remarks of the final panel session was, "there is no value to Canadians to have an unoccupied, unused boreal landbase." Reflecting on the statement, I ponder the various interpretations one could draw from the words "value," "occupied" and "use," in light of the four conference themes. What is valued and by whom? Who or what is occupying the landbase, and in response to what human or naturally induced forces of change? How is the land being used by people and other living things, and how might this use change over time? I judge a good story based on whether it gets me thinking and asking questions after it is told. I am still thinking and questioning based on what was shared in Cochrane, Ontario last October. Boreal Conference 2006 must have told a great story! 